\title{
RDF Fire and Explosion Hazards at Power Plants
}

\author{
Janusz Januszewski ${ }^{1,2}$ and Dorota Brzezińska ${ }^{1, *(D)}$ \\ 1 Faculty of Process and Environmental Engineering, Lodz University of Technology, 90-924 Lodz, Poland; \\ janusz.januszewski@dokt.p.lodz.pl \\ 2 RWE Generation UK Ltd., Swindon SN5 6PB, UK \\ * Correspondence: dorota.brzezinska@p.lodz.pl; Tel.: +48-603-637-633
}

check for

updates

Citation: Januszewski, J.; Brzezińska, D. RDF Fire and Explosion Hazards at Power Plants. Sustainability 2021, 13, 12718. https://doi.org/10.3390/ su132212718

Academic Editor: Xiaolin Wang

Received: 15 October 2021

Accepted: 15 November 2021

Published: 17 November 2021

Publisher's Note: MDPI stays neutral with regard to jurisdictional claims in published maps and institutional affiliations.

Copyright: (c) 2021 by the authors. Licensee MDPI, Basel, Switzerland. This article is an open access article distributed under the terms and conditions of the Creative Commons Attribution (CC BY) license (https:/ / creativecommons.org/licenses/by/ $4.0 /)$.

\begin{abstract}
In the last 30 years Refuse Derived Fuel (RDF) has grown in popularity due to its perception as a readily available, renewable and sustainable fuel for power stations. This increased use of RDF has been closely followed by an escalation of industrial fire and explosion-related incidents associated with this fuel, showing the new hazards and inherent dangers brought by it. The re-evaluation of specific fire and explosion protective measures is required. For RDF to have a continued role as an energy source in a volatile and difficult energy market, it must be perceived as: sustainable; safe; easy; cheap; and reliable. If financial losses due to business interruption occur frequently, then confidence in this area will dissolve, and while safety is paramount to prevent injury and/or death, reputational damage must also be considered to secure energy supply and maintain market confidence in RDF. This paper presents a review of previous investigations and scientific studies, which, combined with the authors' own RDF fire and explosion investigatory experience, allows for a logical hypothesis to be made in relation to relative practices in storage and fuel route fire safety management.
\end{abstract}

Keywords: Refuse Derived Fuel; RDF; RDF fire; RDF explosion; RDF storage; RDF smoldering; RDF self-ignition

\section{Introduction}

The effect of fossil fuels on the environment has instigated an exploration of alternative fuel sources to replace them with other products, in an attempt to reduce environmental impact and secure long-term energy capacity [1]. Historically, RDF technology initially evolved in the USA in the early 1970s [2], and today RDF is established throughout the world in the generation industry and is considered a proven technology.

RDF pellets are the end product of sorted Municipal Solid Waste (MSW); the combustible and non-combustible parts are separated, and the combustible extracts are then manufactured into a form, such as pellets or briquettes, that can then be effectively fired in a generation boiler and classified by BS EN ISO 21640: 2021 [3].

RDF has gained prominence as an alternative fuel due to the vast quantity of nonrecyclable combustible waste materials that can be diverted from landfill and transformed into a product that can be used to replace traditional generation incineration fuels $[4,5]$.

It is recognized that the efficient use of RDF as an energy resource contributes to a recycling-based society [6]. The RDF technology contributes towards managing MSW, and RDF incineration without doubt reduces waste volume. This is particularly important in highly urbanized areas where waste volumes are significant. In addition, combining MSW with energy recovery, in any form, such as Waste to Energy, is an effective method of waste disposal that unquestionably reduces landfill; however, the drawback to this is that it is still reliant on combustion technology, which contributes to pollutants and noxious emissions. Strict guidelines on the emission levels of certain toxic substances that are harmful to human health are essential for this technology to remain credible and sustainable as a renewable source of energy [1]. 
It is not expected that the continued global growth in RDF manufacture is likely to diminish in the near future, and the presented research concentrates on associated safety issues. It is important that the material handling, storage and bulk transport of RDF be perceived as safe, in order for the industry to recognize it as a readily available and non-hazardous fuel [5].

RDF fires are notoriously difficult to detect and extinguish when in enclosed storage spaces and can last for days or even weeks $[3,7,8]$. Additionally, under conducive circumstances, the effluent from RDF deep-seated smoldering fires can lead to explosions [1,2,7,9-15]. Until the recent introduction of BS EN ISO 21912:2021 [10], which covers the safe handling and storage of solid recovered fuels, there was no specific guidance on fire protection. It is therefore important and necessary to review current practices within RDF pellet fuel handling and fuel storage, to prevent or at least mitigate future accidents to make the industry as safe as possible. Incidents spanning a period of over 30 years in industrial power plants provide no doubt that the handling and storage of RDF, due to its physical characteristics, involves a tangible risk of fire and explosion. The number of historical fire and explosion incidents has shown that there is a possible risk of injury and/or death linked with pellet storage; consequently, appropriate and effective safety measures must be applied.

Unfortunately, RDF tends to generate heat spontaneously and this heat build-up can be a major risk, especially within large bulk storage. This can then be further exasperated when certain conditions align, and heat generation from within the pile can lead to thermal runaway and spontaneous ignition [1,4,11-13].

The potential for RDF self-heating seems to vary considerably and can be affected by a wide range of factors, such as: producer/manufacturer; batch; segregation process; and season (this is mainly due to the unpredictable nature of the MSW received at sorting centers). Other factors such as ageing and/or degradation (due to different material handling methods), storage type and localized environment can additionally affect the fuel's characteristics $[2,6,11,12,14-24]$.

Evaluating scientific papers based on historical investigations (following fires and/or explosions) at RDF sites around the world provides an insight into the behavioral characteristics and the suspected reaction of RDF in fire conditions. It is widely recognized, through the volume of research carried out, that the increased use of RDF pellets in power generation has not been without its problems. One of the influencing reasons could be that there was no formal definition or recognized standard guidance for RDF which, to date, has normally been classified as waste and was often regulated as such. The previous lack of recognized standards applied to the procedures associated with production, handling/transport or end use possibly contributed to the major fire and explosion occurrences.

This study was undertaken to review the direct cause(s) which have given rise to this type of incident, often without much of a reaction from regulators or the wider generation industry. Further aims of the study are to look at existing practices within the RDF pellet fuel handling and fuel storage industry, with a view to:

- Increase understanding of RDF in the energy and power industry sector.

- $\quad$ Explore the background of the current scientific understanding of RDF explosion risks.

- Review the literature concerning RDF ignition, fire and explosion.

- Improve awareness of fire investigation in the field of RDF explosions.

- Improve the comprehension of the safety advice available on this topic.

The issues to be solved are:

- The actions that should be taken to reduce the risk at RDF power generation sites.

- Possible causes and lessons that can be used to improve the material handling processes.

- $\quad$ Recommendations to assist in reducing the possibility and frequency of similar events. 


\section{RDF Manufacture}

The last 20 years have seen a worldwide increase in such RDF incidents $[11,14,16]$, ranging from minor to major (fires and explosions), with the most significant examples documented in Japan [8,25], Europe [26,27] and the USA [28]. Some of these incidents, unfortunately, have led to serious injuries and loss of life. During this period, there was no initiative to develop specific guidance standards that could be applied to the procedures associated with production, handling or use of RDF fuel by regulators, insurers, trade associations or 'end-users', such as generation companies.

Standard RDF production involves the removal of non-flammable materials (metal, glass, etc.,) from MSW, which is then usually shredded into small pieces. The shredded MSW is dried and then compressed into a column approx. $50 \mathrm{~mm}$ to $100 \mathrm{~mm}$ by $20 \mathrm{~mm}$ at $100{ }^{\circ} \mathrm{C}$ under pressure to form pellets.

Alternatively, the final form can also be in the shape of briquettes or slugs [6]. Densifying the waste (compacting into a fraction of its initial volume), by pelletizing, briquetting or slugging, creates the fuel source from waste.

Shredding and/or sieving is widely used in the manufacturing process to convert MSW into an RDF product, which makes it more efficient as a fuel due to particle size reduction. Simply summarized, the MSW fuel to RDF pellet production process can be described as:

- Separation;

- Drying;

- Screening;

- Size production;

- Pelletizing/Briquetting/Slugging;

- Cooling;

- Packing.

Whilst manufacturers aim for uniformity of product, the nature of MSW and its wideranging composition makes this practically impossible, and further problems can arise if the pellets are paper- or plastic-rich. RDF pellets that are poorly manufactured or poorly stored are susceptible to disintegration and can start unravelling [1]. Moreover, MSW by character is highly variable and constantly changing in composition and morphology, and other influences on content, such as country/region, mean that the quality and composition of RDF pellets can be affected. The quality of pellet can further be influenced by additional factors such as: the manufacturing process; processing and mixing post manufacture; source; season; and type of final combustion. This all impacts the final manufactured RDF product $[4,26]$. In turn, all of these factors can also influence heat generation and ignition within the stored RDF.

Hence, the calorific value of RDF pellets - the amount of heat released during the complete combustion process — can be very variable, anything between 18 to $28 \mathrm{MJ} / \mathrm{kg}$ [29-31] (even as high as $36 \mathrm{MJ} / \mathrm{kg}$ with a high organic waste content [32]), but this is subject to trends in the use of solid recovered fuels [33,34].

The only way to know the true calorific value would be test every batch using a recognized method, such as BS EN 15400: 2011 Solid recovered fuels-Determination of calorific value [35] or the latest version of BS EN ISO 21654: 2021 Solid recovered fuelsDetermination of calorific value [36-39]. Figure 1 demonstrates typical 6 and $8 \mathrm{~mm}$ RDF Pellets. 


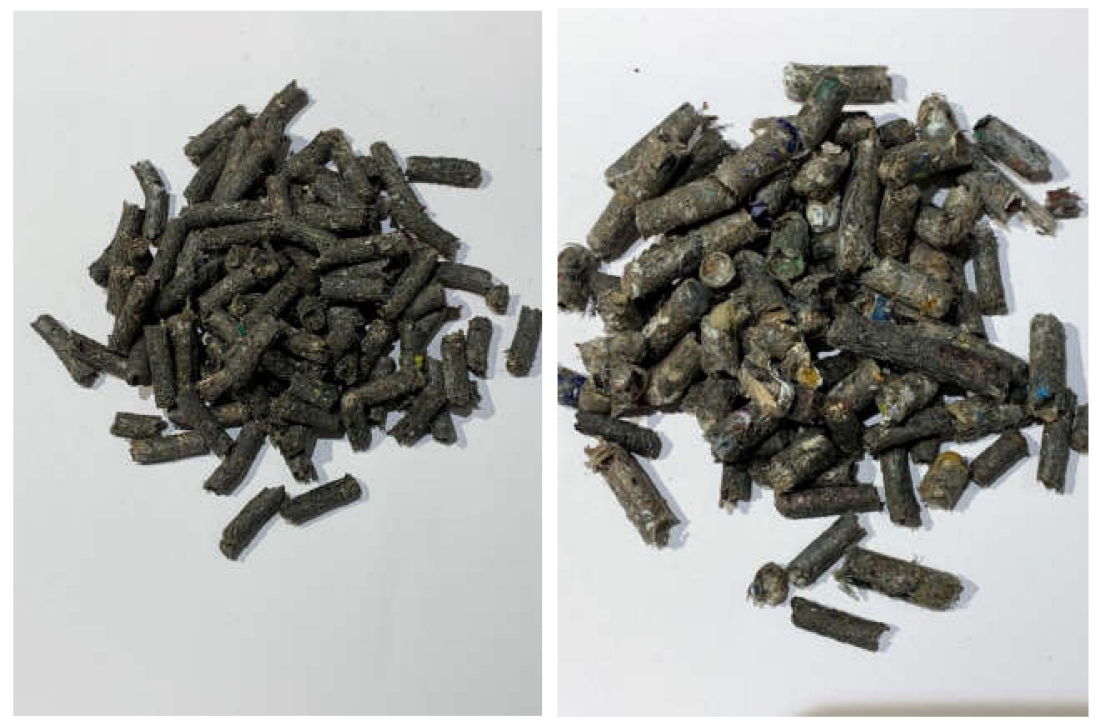

Figure 1. Typical 6 and $8 \mathrm{~mm}$ RDF Pellets (photo-J. Januszewski).

\section{RDF Production and Storage Hazards}

Some manufacturers claim that RDF pellets can be stored for up to 3 years without significant biological or chemical degradation $[5,15,18,20,24,40-45]$, but the operational experience of the authors and RWE Generation shows that these claims are supposed rather than supported; hence, they can be misleading and potentially dangerous (Figure 2).

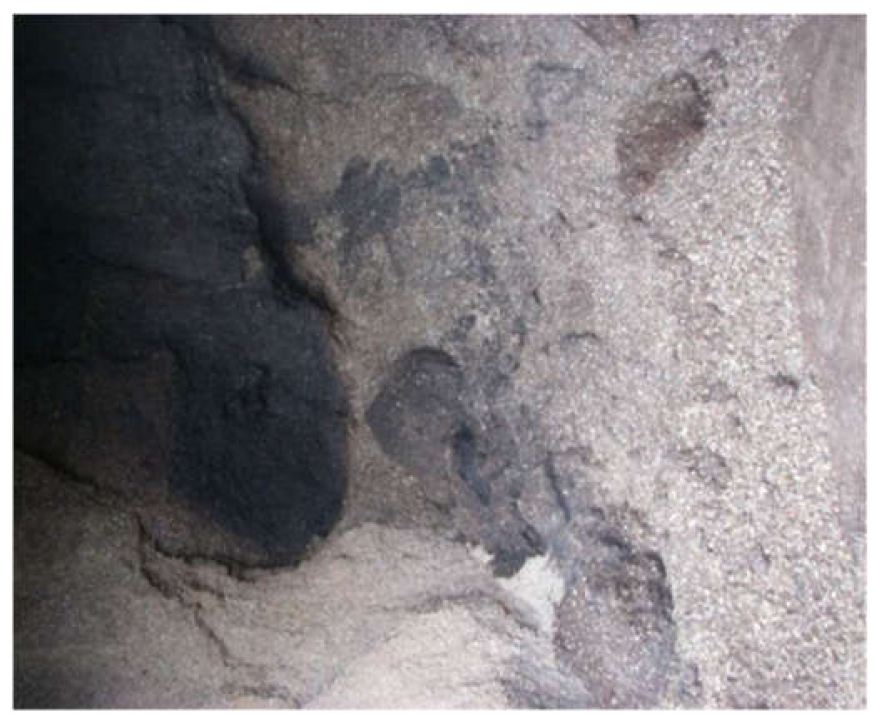

Figure 2. Smoldering RDF (photo-J. Januszewski).

To date, many studies have shown that the problems associated with RDF pellets have been due to factors such as the poor quality of the product. This significant variability can have a direct influence on biological and chemical stability [37-39,41-44,46-48].

Several further important factors should also be considered when deciding on suitability of storage, but the key issues to consider in the self-heating process and overall factors relating to the basis of storage awareness should follow the stages presented in the flowchart Figure 3. 


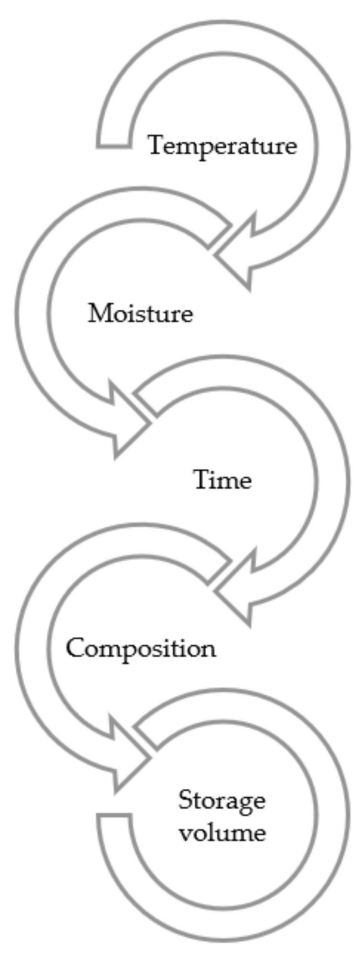

Figure 3. RDF storage awareness.

Based on the authors' experience in industrial fire safety, investigation and standards development, RDF should not be stored for extended periods of time If this proves necessary, the preplanning of storage systems to ensure that they are emptied will help reduce and prevent spontaneous ignition incidents. It seems that the current knowledge of fire in RDF storage has insufficiently implemented insights from past incidents, allowing for gaps in current expertise. Guidelines also appear to be ill-informed, as is clearly demonstrated in the shortcomings of various manufacturers' safety data sheets.

In the authors' opinion, hazards relative to RDF storage are not accurately identified in safety datasheets, and accompanying recommendations are misguided or misleading. It has to be realized that the lack of sufficient warnings or suggested methodology in fire-fighting to assist in dealing with fire incidents proficiently could have severe consequences.

When originally presented as a fuel source for power plants, RDF was perceived as a stable and safe solid fuel. This point of view somewhat changed when a number of spontaneous ignition incidents occurred in RDF storage that led to explosions [6].

Despite the span of time that has passed since these first early incidents, and the amount of research completed to date on numerous fire and/or explosion incidents (involving RDF) [26,27], typical Safety Data Sheets for RDF are still showing inaccurate, insufficient and incomplete information, with inadequate safety warnings of the hazards associated with: fire-fighting; handling and storage; stability and reactivity; and ecological information. Figure 4 shows exemplary damages following an RDF fire and explosion. Therefore, the advice given by manufacturers in the form of product safety data sheets should be reviewed and updated as a matter of urgency. 


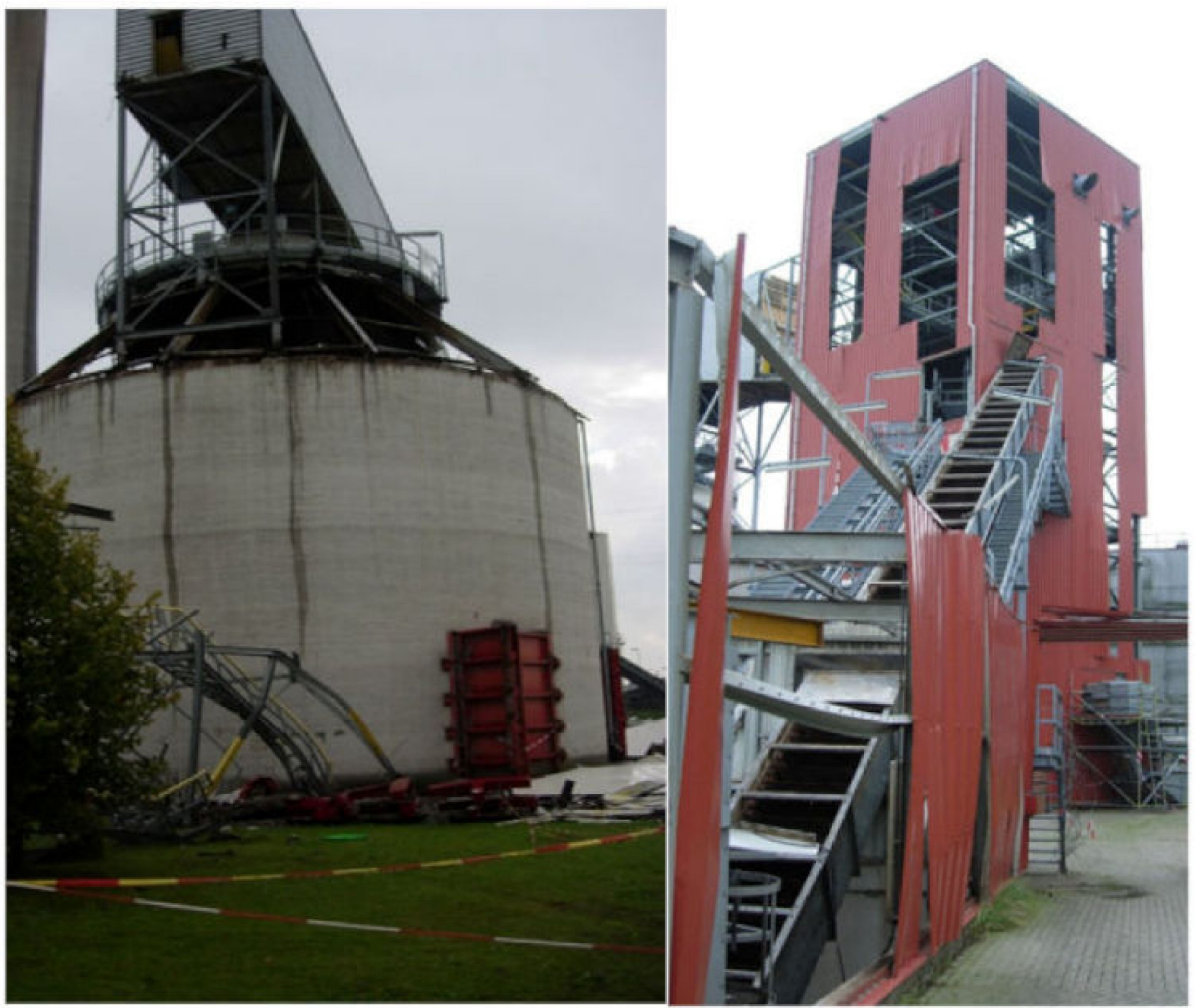

Figure 4. Damage following RDF Fire and Explosion (photo-J. Januszewski).

\subsection{Pyrolytic Behavior of RDF}

A conceivable process of spontaneous ignition at ambient temperature is called chemical oxidation. It is thought that, when RDF is in contact with air, oxygen is absorbed. Then, in the consequent resulting reactions, heat and microorganisms metamorphose into a reactive peroxide, which is the process that is able to cause spontaneous ignition [8,35].

Bulk storage fires in silos, external piles or building storage can generally be defined as one or more of the following:

- Surface flaming;

- Surface smoldering;

- Subsurface smoldering;

- $\quad$ Deep seated fire $[16,22,37,39,41-44,47,49,50]$. 
It is important to emphasize that the discovery of any one of these stages does not necessarily mean that the fire is in its very initial stages. Once a bulk RDF storage fire is established, it can transform between any of the above stages (but this is partly dependent on the starting point and the actual source of ignition). If the fire has sufficient oxygen (air) it may also have the energy to descend into the stockpile and become deep-seated. During this period, the energy dissipates into the surrounding material and/or structure until it becomes totally oxygen controlled, and to a certain degree festers, until exposed to air and a fresh supply of oxygen [51,52].

Gao et al. [12] concluded that the pyrolysis process of RDFs from different manufacturers are all similar and that the main "organic elements" of the pyrolysis process happen in a temperature range of $150{ }^{\circ} \mathrm{C}-550{ }^{\circ} \mathrm{C}$. They deduced that the activation energy at ignition temperature was $89.82 \mathrm{~kJ} / \mathrm{mol}$.

Critical ignition temperature was predicted by Frank-Kamenetskii theory (F-K theory), and the relation between Tc and the height of the RDF pile was calculated, worryingly revealing that $40{ }^{\circ} \mathrm{C}$ would be a sufficient temperature to ignite a $5 \mathrm{~m}$-high pile of RDF [1].

Most academic papers on this subject utilize the F-K theory, but the only drawback with most of the theoretical deductions on RDF was noticed by Blomqvist and Persson, who postulated that that any increase in moisture or humidity limits the F-K theory, due to no account being taken of moisture transport and the accompanying phenomena of hydrolysis, evaporation and condensation. Their reasoning is that the role of water-intervened reactions cannot be handled by the Frank-Kamenetskii method [18].

The serious limitation to engineering methods, regarding their application to the storage of RDF fuel, is that no account is taken of the low-temperature processes that occur before the oxidative effects commence. Hence, a more complete model should include the preliminary creation of heat by microorganisms [21].

In theory, the bulk of RDF should be paper, card, wood, plastics and fabric textiles. This diversity in structure means that there are differing levels of thermal degradation for every component within the RDF; thus, during pyrolysis, the assessment of the pyrolytic behaviors of the RDF mixed materials becomes more complex [45].

Cepeliogullar et al. states that Thermogravimetric Analysis (TGA) is generally needed to examine the thermal behaviors of RDF materials [44], and they provide data on mass loss characteristics to explain the materials' properties and behaviors at high temperatures. This detailed thermal depiction of pyrolytic behavior should be an important consideration when evaluating the entire industrial process in any project.

A summary of the changing heating rates affecting the mixed materials' pyrolytic behaviors was given in The Journal of Analytical and Applied Pyrolysis. Along with TG (Thermogravimetric) and DTG (Derivative thermogravimetry) curves, they summarize the important peak temperatures and amount of residue after pyrolysis. What seems obvious is that the thermal decomposition of RDF can be broken down into four distinct stages [45].

These are:

- Moisture removal;

- Decomposition of cellulose and hemicellulose;

- Decomposition of plastics;

- Char-gas interactions at high temperatures.

Even though the composition of RDF varies from area to area, researchers tend to agree that RDF decomposition is mainly related to the degradation of cellulosic and plastic components, together in tandem with humidity/moisture [45].

\subsection{RDF Self-Heating and Spontaneous Ignition}

Following a number of suspected spontaneous ignition incidents (post 2000) at Power Station RDF storage facilities, mainly in Japan, Yasuhara et al. [1], studied storage conditions that could replicate and induce spontaneous ignition in RDF samples to help try and understand this phenomenon. 
Their observations showed that when the initial temperature of different RDF samples were constant, the samples with a higher moisture content had shorter induction times. Another factor that influenced induction times was, unsurprisingly, the size of the RDF sample, and, interestingly, they observed that there was no connection between bacterial fermentation and spontaneous ignition [6]. However, this may have been down to the nature of the experiment, given two very important aspects: the first being that the samples were kept in a nitrogen stream for $1 \mathrm{~h}$; and the second that the size of the samples was initially $10 \mathrm{~mm} \times 10 \mathrm{~mm}$, by they were ground to less than $2 \mathrm{~mm} \times 2 \mathrm{~mm}$. A true evaluation of the connection between bacterial fermentation and spontaneous ignition would require replication of the storage conditions found at power stations, similar to Persson's experiment on silos with biomass pellets [22].

Babrauskas, in the Ignition Handbook, describes spontaneous combustion as observable smoldering or flaming caused by thermal runaway [38], which in turn is defined as selfheating which rapidly accelerates to high temperatures. He also points out that there is no commonly recognized definition of spontaneous combustion, and suggests that his is the most reasonable one [52].

In accordance with accepted fire engineering principles, the NFPA state that it can generally be accepted that the higher the oxygen concentration, the less energy required for ignition and the quicker the flame spread rate [44].

As temperature increases, the energy required for ignition reduces to a point when the temperature is high enough to cause spontaneous ignition. This minimum temperature point is known as the spontaneous ignition temperature, auto-ignition point or self-ignition temperature; simply put, it is the minimum temperature at which self-heating properties of the material lead to ignition or ignition occurs by itself in the absence of any additional ignition source [53].

On the other hand, the Yasuhara et al. research paper [11] unsurprisingly suggests that how and when the spontaneous ignition of RDF occurs depends on many unknown factors which could cause chemical oxidation reactions under certain storage conditions. More importantly, though, they state that initial temperature, moisture content and the size of the samples are the important factors which must be known to ensure the safe use and storage of RDF.

Another observation is presented by Koseki et al. [24], who, as part of their assessment of hazardous fuels generated from waste, found that the measurement result (heat generation starting temperature and calorific value) showed that RDF samples generated more heat after water is added, and, moreover, it is suspected that fermentation played a role in the heat generation of the RDF and wooden pellets (bark). This is significant because it shows heat generation starting at much lower temperatures than is currently considered as hazardous within the generation industry. His results are presented in Table 1.

Table 1. Heat generation starting temperature and calorific value [24].

\begin{tabular}{ccccc}
\hline Sample & $\begin{array}{c}\text { Heat } \\
\text { Generation } \\
\text { Starting Temp } \\
\left({ }^{\circ} \mathbf{C}\right)\end{array}$ & $\begin{array}{c}\text { Rising Temp } \\
\left({ }^{\circ} \mathbf{C}\right)\end{array}$ & $\begin{array}{c}\text { Peak } \\
\text { Temperature } \\
\left({ }^{\circ} \mathbf{C}\right)\end{array}$ & $\begin{array}{c}\text { Calorific Value } \\
(\mathbf{J} / \mathbf{g})\end{array}$ \\
\hline RDF & 51.3 & 70.1 & 97.7 & 19.5 \\
RDF + Water & 29.5 & 36.1 & 65.0 & 14.4 \\
$(20 \%)$ & & & & \\
\hline
\end{tabular}

On the basis of the authors' own experience and observations, it could be summarized that waste fuel varies from other fuels, as mentioned previously, due to its diversity, and therefore it is more difficult to theoretically define the processes of what happens during the storage of waste fuels [26,27]. 
However, spontaneous combustion, being an exothermic process, is reliant on combustible material and an increasing temperature along with sufficient oxygen to evolve. It is also reasonable to deduct that traces of metals may intensify the rate of self-heating. Plus, ignition and temperature development are reliant on other factors, such as:

- Particle size;

- Amount of organic material;

- Moisture content;

- $\quad$ Size of the waste pile;

- Surface area of the waste fuel available to reaction;

- $\quad$ The pressure over the pile.

\subsection{RDF Smoldering Storage Fires}

The authors' analysis of past incidents $[2,11,14,17,23,24,54]$ confirms that a number of those incidents have been attributed to the shortcomings in the management of the risks involved with RDF. Greater analysis of incidents also reveals that, usually, large volumes of RDF fuel was present, which has generally led to a repeating pattern in incidents, that in its simplest form can be summarized as shown in Figure 5.

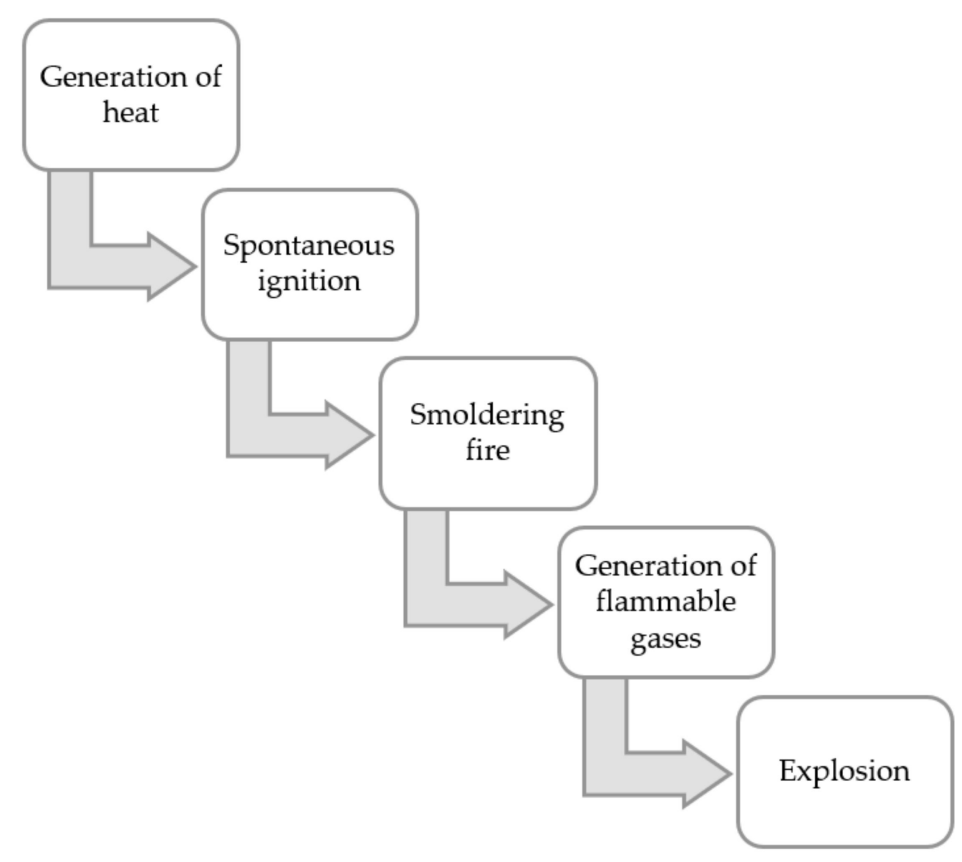

Figure 5. Steps from RDF heating to explosion.

It can further be sensibly assumed that the addition of moisture quickens the trigger processes to fire, and once fire occurs, there is a real possibility of explosion if conditions align.

Gao and Hirano [14], as far back as 2005, depicted a summary of the process of an RDF gas explosion that occurred at a refuse-derived fuel (RDF) storage silo fire involving two fatalities in Japan. Their described timeline is extremely insightful, not just in that it reveals the difficult aspects of tackling an RDF storage fire, but because their research also discussed the Mie explosion in Japan in 2003 and how the first gas explosion in this case occurred on August 14, 2003, and although this explosion was weak, the sudden blow-out of hot gas still managed to injure four workers. The second explosion occurred a full five days later, on August 19, 2003, unfortunately killing two firefighters. The significant point here is that, according to the investigation, the fire started on 27 July 2003 and despite best efforts proved very difficult to extinguish. An important indicator in the research refers to a recorded rise in temperature seven days previously (July 20, 2003), and it is at this 
stage that they describe observed abnormal temperature rises occurred, jointly with steam generation being observed [14]. In this instance, due to the abnormal temperature rise, it is reasonable to suspect the very probable scenario that a sub-surface storage fire was already in progress and probably well developed.

This also shows that bulk storage arrangements are susceptible to spontaneous ignition and fires originating internally, such as sub-surface smoldering fires which are notoriously problematic to detect, especially in the initial stages.

Particular concerns have arisen around the preconceived critical temperature of RDF for spontaneous temperature rise in relation to the pile size. Gao and Hirano [14] declared, theoretically, that as the size of the pile increases, the critical temperature decreases, further adding that if the size of the pile is taller than $15 \mathrm{~m}$, spontaneous temperature rise can occur at temperatures of less than $20^{\circ} \mathrm{C}$.

The NFPA classifies pellets in bulk storage as typically stored in silos, bins, tanks, or in large piles on the floor [30]. The Ignition Handbook further explains that fires in large piles tend to burrow down, making them difficult to extinguish, and that this type of fire requires prolonged soaking to reach the seat of the fire. But the truth is that it is far more complicated, as outlined in Babrauskas's discussion of smoldering fires [52], and while this may be fine when a storage pile in an open air, this simple approach should not be considered a recognized method of extinguishment for silos or RDF pellets due to moisture absorption and the dangers associated with adding water during protracted silo incidents [22].

Furthermore, post-fire or explosion investigations should place an onus on the quantity of burnt RDF found within the silo. Furthermore, temperatures should be noted during excavation, as this can assist in diagnosing the rate of smoldering formed and provide a basis to analyze the length of time the RDF had been smoldering before the fire or explosion event.

Sakka et al. reported in Bioscience, Biotechnology, and Biochemistry (2005) [10] that they had observed that RDF pellets contain a high count of viable bacterial cells, and that these bacteria generate heat and hydrogen gas during fermentation and particularly under wet conditions. In the study, they analyzed bacterial cell numbers produced by RDF with various dilutions of calcium hydroxide (added to prevent rotting and to aid drying). This was done to establish the quantities of hydrogen gas produced in wet conditions. Additionally, they studied microflora of the RDF before and during fermentation and discovered that the samples contained a variety of clostridia able to produce hydrogen gas. In summary, they discovered significant quantities of spore-forming bacteria (such as Clostridium) that survived during the hot air drying process and still went on to produce hydrogen gas from the organic constituents in the RDF (when in wet conditions) and speculated that the explosion at Mie RDF Power Station was caused by an increase of hydrogen gas produced by anaerobic bacteria, due to the fire-fighting water poured into the silo in an attempt to extinguish the fire. But there are a number of questions left unanswered by this theory, such as: what quantity of water was added, and over what period of time? Furthermore, is it possible that sufficient quantities of hydrogen could be produced in this type of process over such lengthy fire-fighting operations?

\subsection{RDF Explosions}

Despite the continued claims RDF being a safe and stable fuel, jointly with the prevaricated claims of its good storage ability, explosions and subsequent fires have occurred on a regular basis throughout the last 30 or so years $[11,12,14,17,18,22,24]$. The prominent RDF fire and explosion incidents had serious consequences, and it seems that past lessons were not studied sufficiently, nor taken into account in more recent RDF projects.

Having reviewed a number of papers, the similarity of pyrolysis behavior is evident at low temperatures between RDF and wood pellets (cellulosic material being present in both), but with apparent distinctions at higher temperatures $[1,24,40,55]$, where analysis shows 
that the burnt samples heated to temperatures of $350{ }^{\circ} \mathrm{C}$ and beyond generate volatile gases from the fuel along with a softening and clustering of the RDF pellets.

The RDF production processes involving MSW (especially composition variability), clearly impacts more profoundly on the characteristics and behavior of RDF pellets than with wood pellets.

The degree of sterilization of RDF during the production process is usually unknown or unquantified; manufacturer data sheets normally state that the pellets are biologically inactive. However, pyrolysis within the silo suggests that this may not be the case as self-ignition of RDF in silos is evidently possible [1].

Moreover, ignition of explosions may be caused by the abrupt release of trapped lowweight volatiles, creating the right gas stoichiometry for an explosion. Another possibility is when temperatures within the pile reach beyond auto-ignition temperatures, generating smoldering long enough to create explosive or volatile gases from the produced effluent.

Collecting the experience and research knowledge on RDF production and storage hazards, presented above in Section 3, the self-heating and thermal runaway and fire and explosion development processes consequences and key-factors can be summarized as shown in Table $2[16,39,44,47]$.

Table 2. Key stages in the fire and explosion development processes.

\begin{tabular}{|c|c|c|c|}
\hline Phenomenon & Process & Consequence & Key Factors \\
\hline Self-heating & $\begin{array}{c}\text { Bio-chemical } \\
\text { self-heating } \\
\mathrm{T}<70{ }^{\circ} \mathrm{C}\end{array}$ & $\begin{array}{c}\text { Formation: } \\
\mathrm{CH}_{4} \text { and } \mathrm{CO}_{2} \\
\text { Temperature } \\
\text { increase }\end{array}$ & $\begin{array}{c}\text { Presence of } \\
\text { micro-organismsComposition } \\
\text { Moisture content } \\
\text { Storage volume } \\
\text { Temperature-ambient } \\
\text { Time-age }\end{array}$ \\
\hline Thermal runaway & $\begin{array}{l}\text { Low temperature } \\
\text { oxidation } \\
\mathrm{T}>50^{\circ} \mathrm{C}\end{array}$ & $\begin{array}{c}\text { Formation: } \\
\mathrm{CH}_{4}, \mathrm{CO} \text { and } \mathrm{CO}_{2} \\
\text { Temperature } \\
\text { increase }\end{array}$ & $\begin{array}{c}\text { Storage volume } \\
\text { Temperature-ambient } \\
\text { Time-age }\end{array}$ \\
\hline Fire & $\begin{array}{l}\text { Smoldering } \\
\text { pyrolysis } \\
\mathrm{T}>250{ }^{\circ} \mathrm{C}\end{array}$ & $\begin{array}{c}\text { Formation: } \mathrm{CH}_{4}, \mathrm{CO} \\
\text { and } \mathrm{CO}_{2} \\
\text { Temperature } \\
\text { increase }\end{array}$ & $\begin{array}{l}\text { Oxygen level } \\
\text { Storage volume } \\
\text { Temperature }\end{array}$ \\
\hline Explosion & Explosion & $\begin{array}{l}\text { Pressure wave } \\
\text { Secondary } \\
\text { explosions } \\
\text { Secondary fires }\end{array}$ & $\begin{array}{c}\text { Level of effluent gases } \\
\text { Ignition source } \\
\text { Oxygen }\end{array}$ \\
\hline
\end{tabular}

\section{RDF Fire Hazards Mitigation}

Experience has shown that power station conversions to a new fuel using the same materials handling methods and equipment, designed for the previous or original intended fuel, without a proper fire engineering re-evaluation of plant suitability (for the properties and behaviors of the new fuel) is not a safe option. Many times, the detection and suppression equipment is presumed adequate, whereas a complete technical evaluation is required.

Given that RDF fires are extremely difficult to extinguish it should be remembered that fires could last for days or even weeks [56]. Additionally, given the correct circumstances, the effluent from RDF smoldering fires within a pile can lead to explosion(s), possibly causing severe injuries and even the loss of life. In addition, there are also business considerations due to the subsequent severe interruptions, not forgetting the importance of the security of electricity supply.

The difficulties of RDF fire hazards mitigation begin with the notoriously problematic factor of discovery of a fire within the storage pile; they then, more often than not, continue throughout the entire fire-fighting operations process. 


\subsection{Fire Detection}

From the authors' own experience, it can be stated that deep-seated silo fires are particularly challenging to detect, especially during the incipient and medium stages (hours and days) of the fire, and certainly before any physical (visual or olfactory) signs appear [27]. Deep-seated fires can smolder for some time, and measuring (certain) gas concentrations (such as $\mathrm{CO}$ and $\mathrm{CO}_{2}$ ) in combination with temperature monitoring is currently the most common method of detection used to establish the presence of fire within indoor fuel storage (silo or building) [28].

Through experience, this method shows that ignition deep within the pile puts limitations on the claimed effectiveness of any multi-gas detection commonly used in silo head spaces [27].

By its nature, the detection is commonly aimed at the introduction of an ignition source through the fuel route (which is more likely during filling operations); therefore, any burning is expected to be nearer the surface. Hence, these volatiles can build up unnoticed in conjunction with the present accelerating self-heating process in the surrounding area until becoming totally oxygen-controlled $[27,28]$. Further complications to detection exist in the form of hardened plastics (bonding and clustering RDF pellets), that can form caps within the pile, due to prolonged repeated cycles of heating (from smoldering) and cooling (during the oxygen-controlled phase) The caps formed within the RDF pile block the volatiles from rising with sufficient quantity and buoyancy to activate the detectors in the top of the silo head space.

Generally, indoor or enclosed self-heating fires are deep-seated and not detectable until the fire is reasonably well-developed and the headspace or basement of the storage structure starts showing the incipient stages of fire or starts filling with combustible and/or incomplete combustible gases. Of course, in external storage piles, where the gases can simply disperse, this is less of a problem [22].

Therefore, a method to achieve earlier detection would be an important component of any recommendations proposed for the improvement of fire safety protection. It is only by studying the trends within fire, along with the effluent measurements and temperatures, that we might be able to gain an earlier indication of possible abnormal conditions within RDF fuel pile bulk storage.

Such an advantage would allow operators to deal with abnormal conditions sooner, resulting in a more timely (and consequently, probably more effective) intervention.

\subsection{Fire-Fighting and Fire Suppression}

Suzuki et al. [7] conducted a study on the extinction of an RDF pile and observed traits of fire growth and extinction to try and create a foundation for fire control. They found that RDF pellets clustered when heated, due to the plastics contained in the pellets melting and working as a bonding agent.

When applying water to the fire, the bonded/clustered pellets were cooled and formed a coating which prevented water from penetrating the pile; the pellets underneath (within the pile) remained hot with continued oxidation, and when exposed to air again, flaring, heat and smoke re-emanated from the pile [7].

Therefore, fire-fighting an RDF pellet fire is unlike most fires and generally water jets should not be used. Experience shows that a water spray is only suitable for indoor RDF surface fires to prevent flaring, and only for short periods of time, due to the possibility of the swelling or unravelling of pellets and the hazard of extra structural stress to the weight loading, due to the retention of water within the pellets or unraveled material that could possibly impact structural integrity.

There is also another reason for limiting water. In an experiment by Persson [21], involving a silo and biomass pellets, he warns about adding water due to concerns that in certain circumstances this could contribute to the formation of explosive combustible gas. This water-gas reaction, $\mathrm{C}+\mathrm{H}_{2} \mathrm{O} \rightarrow \mathrm{H}_{2}+\mathrm{CO}$, occurs when fire-fighting water comes into contact with temperatures above $700{ }^{\circ} \mathrm{C}$, resulting in the production of hydrogen [20]. 
Hogland and Marques [18] carried out a study on storage to instigate spontaneous combustion within an RDF storage pile. This was to assess the feasibility of the long-term storage of waste fuel. The RDF part of the experiment disclosed that spontaneous combustion was observed after approximately 6 months. Their observations were important, as they indicated that no flaming ensued unless an effort was made to excavate the fire, as excavation would reenergize the flaming to burst forward. They also deducted, not unreasonably, that this would denote that the pyrolysis within the pile was oxygen-limited, further reinforced by the specific stench of gases associated with incomplete oxidation and partial combustion of hydrocarbon mixtures. Fire service attempts to extinguish the fire with water onto the pile were unsuccessful and the wetting produced polluted fire-water run-off. After 3 days the fire accelerated, and the original pile was broken down and spread out. This turned out to be the most effective and efficient way of extinguishing the fire, with the fire then burning out within 5 days.

In summary, it is clear that having a ready, easy way of emptying the storage facility would be advantageous and even crucial. This would assist in decreasing the risks during fire-fighting operations, and would also help to reduce potentially hazardous and costly protracted incidents. It should be stressed that during emptying operations (as the empty head space volume increases), this must be controlled and nullified from the buildup of explosive gases. It is suggested that this could be done with hi-expansion foam and/or nitrogen gas.

In power generation facilities, this can be applied to fires in bunkers or silos. The hi-expansion foam should be applied from the top into the headspace to prevent buildup of fire effluent gases, whilst nitrogen gas should be applied through the bottom. Both hi-expansion foam and nitrogen systems are best served via a preinstalled fitted system, but in older facilities these measures can still be deployed and applied with the use of mobile foam generators or, in the case of nitrogen, by lance [20].

It should be remembered that silo fire-fighting is a difficult and specialized skill, and the basis of any silo fire safety strategy should always be to prevent the introduction of an ignition source, whilst at the same time being aware that hot spots can develop in any part of the material. Moreover, whilst conventional convection within a storage pile has a tendency of ascending and descending, if an air source (providing oxygen) to the fire comes from another direction (top, below or side, i.e., from basement galleries), this will cause smoldering to move from the ignition towards the air source, and if this is in a downward direction, this can potentially create capped cavities or effluent gas-filled voids within the stored RDF pile. Fascinatingly, forensic investigations into silo fires have evidenced long fingers of carbonized material stretching and being drawn towards gaps and available air sources [50].

\section{Conclusions}

For RDF to have a continued role in a volatile and difficult energy market, it must be perceived to be a truly sustainable, easy, cheap and reliable energy source. If financial losses due to business interruption occur frequently, then confidence in this sector will dissolve. Further, whilst safety is paramount to prevent injury and/or death, reputational damage must also be considered at the same time, as a secure energy supply will maintain market confidence.

Findings show that temperature, moisture content, time, composition and storage type (preferably dry), along with volume, are important key factors in the self-heating process of RDF. These must be evaluated and known to ensure the continued safe use and storage of RDF pellets.

RDF manufactured from MSW shows significant risk (due to a low self-heating $\left(75^{\circ} \mathrm{C}\right.$ $\pm 5^{\circ} \mathrm{C}$ ) start up temperature) of self-ignition. Chemical oxidation is a significant factor for the generation of internal heat reaching a state of self-ignition due to the components of RDF being very susceptible to chemical oxidation. 
It appears from the reviewed studies that self-oxygenating is a factor in RDF pellets. On several occasions, visible pointers in the studies have referenced the ability of pellets to sustain self-smoldering fires, and where clustering/capping has occurred this indicates that self-oxygenation is the only probability of the fire sustaining itself. High moisture content also has a big influence on self-heating and self-ignition, as RDF pellets react with water/moisture/humidity. Moisture content at or over $20 \%$ causes a change in the material, beginning chemical oxidation and self-heating with ignition values in the region of $75-85^{\circ} \mathrm{C}$. Due to this, temperatures in stored piles above $70{ }^{\circ} \mathrm{C}$ should be avoided, since this seems to be the critical point indicator of self-heating or possibly self-ignition occurring (subject to moisture content).

Fire-fighting jets should be avoided as they can cause the collapse of gaseous caverns and dislodge gases into the free space. If internal smoldering fire temperatures reach above $700{ }^{\circ} \mathrm{C}$, a reaction with water can occur in a water-gas reaction: $\mathrm{C}+\mathrm{H}_{2} \mathrm{O} \rightarrow \mathrm{H}_{2}+\mathrm{CO}$. The best and most efficient method of extinguishing a pellet fire is to be able to spread it outdoors and simply hose it down with a spray, or allow the fire to burn itself out.

When considering the probable-or indeed likely_type of fire scenario, then it must be questioned if the detection methods will provide adequate detection capability early enough to detect a fire.

Acknowledging the chosen detection principle and detector type, and therefore its capability, and recognizing that this will influence the time to activation of the warning system is the first step in identifying any possible shortcomings of system design.

The onset of significant volatile release can be expected between $150-550{ }^{\circ} \mathrm{C}$ [11], and this should be the basis for ensuring that the method of detection selected is the most appropriate for the hazard. Expected fire behavior in the area should be monitored. This will ensure that fire detection is provided at the earliest possible, if not the incipient, stage of fire growth.

Fire safety design and systems evaluation should assess if a fire can be detected, controlled or suppressed and/or extinguished promptly without unacceptable damage to plant, and that:

- it is unable to spread internally beyond the initially ignited fuel;

- $\quad$ it will not spread externally to other buildings or process plant (on or off site);

- it will not cause unacceptable damage to the environment.

In summary, the uniform standards that have been required for some time in the safe handling and storage of RDF pellets in commercial and industrial applications (from manufacturing through to end use), have finally been published in 2021. These newly published international standards provide the principles and requirements for the safe handling and storage of RDF pellets in commercial and industrial applications, and while these have been required for some time, existing RDF facilities should be revalidated to ensure safety measures are adequate.

\section{Future Research}

There are definite gaps in RDF knowledge along with some conflicting findings which are often open to misinterpretation.

The buoyancy and behavioral properties of the effluent (hot and cooled state) or flammable gases produced requires detailed evaluation in small and large scale experiments. These need to look beyond the dust-type explosions and focus on the explosive phenomenon of RDF smoldering gases. The properties of the flammable gas, formed during the smoldering phase, is important because it could be used to prevent similar future incidents, but could also establish when sufficient energy is present in a deep-seated fire to clear the RDF fuel pile. This would assist in assessing an effective detection capability in storage head space and below storage/silo basements. 
Author Contributions: Conceptualization, J.J. and D.B.; writing-original draft preparation, J.J.; writing-review and editing, D.B.; visualization, J.J.; supervision, D.B. All authors have read and agreed to the published version of the manuscript.

Funding: 3rd Edition of the Polish Ministry of Science and Higher Education: Implementation doctorate" (Agreement DWD/3/6012019, 18 February 2020 r.).

Institutional Review Board Statement: Not applicable.

Informed Consent Statement: Not applicable.

Data Availability Statement: Not applicable.

Conflicts of Interest: The authors declare no conflict of interest.

\section{References}

1. Edo, M.; Budarin, V.; Aracil, I.; Persson, P.-E.; Jansson, S. The Combined Effect of Plastics and Food Waste Accelerates the Thermal Decomposition of Refuse-Derived Fuels and Fuel Blends. 2016. Available online: http:/ /www.sciencedirect.com/science/article/ pii/S0016236116302277 (accessed on 13 July 2018). ISBN 0016-2361.

2. Cheremisinoff, N.P. Dust Explosion and Fire Prevention Handbook: A Guide to Good Industry Practices; Wiley: Hoboken, NJ, USA, 2014; ISBN 9781118773505.

3. BSI-British Standards Institution. BS EN ISO 21640:2021 Solid Recovered Fuels—Specifications and Classes; BSI: London, UK, 2021.

4. Sever Akdağ, A.; Atimtay, A.; Sanin, F.D. Comparison of Fuel Value and Combustion Characteristics of Two Different RDF Samples. Waste Manag. 2016, 47, 217-224. Available online: http://www.sciencedirect.com/science/article/pii/S0956053X15301045 (accessed on 13 July 2018). [CrossRef] [PubMed]

5. Sapuay, G.P. Resource Recovery through RDF: Current Trends in Solid Waste Management in the Philippines. Procedia Environ. Sci. 2016, 35, 464-473. Available online: http:/ / www.sciencedirect.com/science/article/pii/S1878029616301190 (accessed on 13 July 2018). [CrossRef]

6. Sakka, M.; Kimura, T.; Ohmiya, K.; Sakka, K. Detection of Hydrogen Gas-Producing Anaerobes in Refuse-Derived Fuel (RDF) Pellets. Biosci. Biotechnol. Biochem. 2005, 69, 2081-2085. [CrossRef] [PubMed]

7. Suzuki, T.; Tsuruda, T.; Ogawa, Y.; Liao, C. A Study on Extinction of RDF (Refuse Derived Fuel) Pile. Fire Saf. Sci. 2005, 8, 789-800. [CrossRef]

8. Suzuki, T. RDF (Refuse Derived Fuel) Fires. J. Jpn. Soc. Saf. Eng. 2014, 53, 418-424. (In Japanese)

9. Japanese National Institute of Industrial Safety. Refuse Derived Fuel (RDF): Risk of Explosion and Fire, and Safe Handling; Japanese National Institute of Industrial Safety: Tokyo, Japan, 2014.

10. BSI-British Standards Institution. BS EN ISO 21912:2021 Solid Recovered Fuels—Safe Handling and Storage of Solid Recovered Fuels; BSI: London, UK, 2021.

11. Yasuhara, A.; Amano, Y.; Takayuki, S. Investigation of the Self-Heating and Spontaneous Ignition of Refuse-Derived Fuel (RDF) during Storage. 2010. Available online: http://www.sciencedirect.com/science/article/pii/S0956053X09004747 (accessed on 13 July 2018). ISBN 0956-053X.

12. Gao, L.; Tsuruda, T.; Suzuki, T. Possibility of Refuse Derived Fuel Fire Inception by Spontaneous Ignition. In Report of Fire Research Institute of Japan; National Research Institute of Fire and Disaster: Tokyo, Japan, 2005; Volume 99, pp. 173-178, ISSN $0426-2700$.

13. Icove, D.J. Kirk's Fire Investigation, 8th ed.; Haynes, G.A., Kirk, P.L., Eds.; Pearson: New York, NY, USA, 2018 ; ISBN 9780134237923.

14. Gao, L.; Hirano, T. Process of accidental explosions at a refuse derived fuel storage. 2006. Available online: https://www. sciencedirect.com/science/article/pii/S0950423005000665 (accessed on 13 July 2018). ISBN 0950-4230.

15. Morrison, D.T.; Hart, R.J. Guidelines for Identifying and Mitigating Thermal Hazards of Sustainable Materials. Process. Saf. Prog. 2012, 31, 174-181. Available online: https:/ / onlinelibrary.wiley.com/doi/abs/10.1002/prs.10505 (accessed on 10 October 2021). [CrossRef]

16. Ogle, R.A.; Dillon, S.E.; Fecke, M. Explosion from a smoldering silo fire. Process. Saf. Prog. 2013, 33, 94-103. [CrossRef]

17. Vasconcelos, C.; Silva, R.B.; Martins-Dias, S. Insight on the Self-Ignition Behaviour of RDF Components; Energy and Environmental Engineering Research Group, Instituto Superior Técnico: Lisboa, Portugal, 2014.

18. Hogland, W.; Marques, M. Physical, biological and chemical processes during storage and spontaneous combustion of waste fuel. Resour. Conserv. Recycl. 2003, 40, 53-69. Available online: https://www.sciencedirect.com/science/article/pii/S092134490300025 9 (accessed on 10 October 2021). [CrossRef]

19. Fu, Z.-M.; Li, X.-R.; Koseki, H. Heat generation of refuse derived fuel with water. J. Loss Prev. Process. Ind. 2005, 18, 27-33. Available online: http:/ / www.sciencedirect.com/science/article/pii/S0950423004000889 (accessed on 13 July 2018). [CrossRef]

20. Li, X.-R.; Lim, W.-S.; Iwata, Y.; Koseki, H. Thermal characteristics and their relevance to spontaneous ignition of refuse plastics/paper fuel. J. Loss Prev. Process. Ind. 2009, 22, 1-6. Available online: http://www.sciencedirect.com/science/article/pii/S095 0423008001198 (accessed on 13 July 2018). [CrossRef]

21. Blomqvist, P.; Persson, B. Spontaneous Ignition of Biofuels—A Literature Survey of Theoretical and Experimental Methods.; SP Swedish National Testing and Research Institute: Borås, Sweden, 2003. 
22. Persson, H. Silo Fires_Fire Extinguishing and Preventive and Preparatory Measures; Swedish Civil Contingencies Agency (MSB): Karlstadt, Sweden, 2013.

23. Koseki, H.; Iwata, Y.; Momota, M. Report on the Assessment of Hazardous Potential of Fuels Generated from the Waste and Spent Materials; National Research Institute of Fire and Disaster: Tokyo, Japan, 2007.

24. Sharuddin, S.D.A.; Abnisa, F.; Daud, W.M.A.W.; Aroua, M.K. A review on pyrolysis of plastic wastes. Energy Convers. Manag. 2016, 115, 308-326. [CrossRef]

25. Yasuhara, A. Chemical Consideration on Spontaneous Incineration Accidents of Refuse-Derived Fuels and Exothermic Reaction Mechanism. J. Jpn. Soc. Saf. Eng. 2006, 45, 117-124. (In Japanese)

26. RWE Generation UK. Technical Inquiry Panel Report-Incident 10 September 2014; RWE Generation UK: Newark, UK, 2015.

27. Januszewski, J. Amer Fire E Explosion Investigation Notes; RWE Generation UK Ltd.: London, UK, 20 September 2014.

28. Alter, H. The history of refuse-derived fuels. Resour. Conserv. 1987, 15, 251-275. [CrossRef]

29. Garcés, D.; Díaz, E.; Sastre, H.; Ordóñez, S.; González-LaFuente, J.M. Evaluation of the potential of different high calorific waste fractions for the preparation of solid recovered fuels. Waste Manag. 2016, 47, 164-173. [CrossRef] [PubMed]

30. Zhao, L.; Giannis, A.; Lam, W.-Y.; Lin, S.-X.; Yin, K.; Yuan, G.-A.; Wang, J.-Y. Characterization of Singapore RDF resources and analysis of their heating value. Sustain. Environ. Res. 2016, 26, 51-54. [CrossRef]

31. Osibote, O.A.; Hlaba, A.; Rabiu, A. Refuse Derived Fuel Pellets as a Renewable Energy Source. Int. Proc. Chem. Biol. Environ. Eng. 2017, 102, 65-72. [CrossRef]

32. Dianda, P.; Mahidin, M.; Munawar, E. Production and characterization refuse derived fuel (RDF) from high organic and moisture contents of municipal solid waste (MSW). IOP Conf. Ser. Mater. Sci. Eng. 2018, 334, 012035. [CrossRef]

33. Martignon, G.P. Trends in the Use of Solid Recovered Fuels; IEA Bioenergy: Paris, France, 2020; ISBN 978-1-910154-72-4.

34. Jewiarz, M.; Mudryk, K.; Wróbel, M.; Frączek, J.; Dziedzic, K. Parameters Affecting RDF-Based Pellet Quality. Energies 2020, 13, 910. [CrossRef]

35. BS EN 15400: 2011 Solid recovered fuels. Determination of calorific value. Available online: https://www.techstreet.com/ standards/bs-en-15400-2011?product_id=1779163 (accessed on 10 October 2021).

36. BS EN ISO 21654: 2021 Solid recovered fuels-Determination of calorific value. Available online: https://standards.iteh.ai/ catalog/standards/cen/c1c285de-0b04-492f-90d2-390a73924503/en-iso-21654-2021 (accessed on 5 October 2021).

37. National Fire Protection Association. NFPA 921: Guide for Fire and Explosion Investigations; NFPA: Quincy, MA, USA, 2013; ISBN 9781455908509.

38. National Fire Protection Association. NFPA 69, Standard on Explosion Prevention Systems; NFPA: Quincy, MA, USA, 2014.

39. Society of Fire Protection Engineers. SFPE Handbook of Fire Protection Engineering, 4th ed.; Dinenno, P.J., Drysdale, D., Beyler, C.L., Walton, D.W., Custer, L.P.R., Eds.; NFPA: Quincy, MA, USA, 2008; ISBN 9780877658214.

40. Van Blijderveen, M.; Bramer, E.A.; Brem, G. Modelling Spontaneous Ignition of Wood, Char and RDF in a Lab-Scale Packed Bed. Fuel 2013, 108, 190-196. Available online: https:/ /www.sciencedirect.com/science/article/pii/S0016236113000495 (accessed on 2 October 2021). [CrossRef]

41. Kluska, J.; Klein, M.; Kazimierski, P.; Kardaś, D. Pyrolysis of biomass and refuse-derived fuel performance in laboratory scale batch reactor. Arch. Thermodyn. 2014, 35, 141-152. [CrossRef]

42. Bhaskar, T.; Uddin, A.; Murai, K.; Kaneko, J.; Hamano, K.; Kusaba, T.; Muto, A.; Sakata, Y. Comparison of thermal degradation products from real municipal waste plastic and model mixed plastics. J. Anal. Appl. Pyrolysis 2003, 70, 579-587. Available online: http:/ / www.sciencedirect.com/science/article/pii/S0165237003000275 (accessed on 13 July 2018). [CrossRef]

43. Kumaran, K.; Sharma, I. Catalytic Pyrolysis of Plastic Waste: A Review; B.Tech Solar and Alternate Energy Amity University Dubai: Dubai, United Arab Emirates, 2020; pp. 1-4.

44. Cote, A.E. Fire Protection Handbook, 20th ed.; NFPA: Quincy, MA, USA, 2008; ISBN 9780064641234

45. Çepelioğullar, Ö.; Mutlu, I.; Yaman, S.; Haykiri-Acma, H. A study to predict pyrolytic behaviors of refuse-derived fuel (RDF): Artificial neural network application. J. Anal. Appl. Pyrolysis 2016, 122, 84-94. Available online: http:/ /www.sciencedirect.com/ science/article/pii/S0165237016300985 (accessed on 13 July 2018). [CrossRef]

46. Beveridge, A. Forensic Investigation of Explosions, 2nd ed.; CRC Press: Boca Raton, FL, USA, 1998; ISBN 9781466503946. (Electronic bk.).

47. Hurley, M.J.; Gottuk, D.T.; Hall, J.R., Jr.; Harada, K.; Kuligowski, E.D.; Puchovsky, M.; Torero, J.L.; Watts, J.M., Jr.; Wieczorek, C.J. SFPE Handbook of Fire Protection Engineering; Springer: New York, NY, USA, 2016.

48. Zhang, B.; Ng, H.D.; Lee, J.H. Measurement and relationship between critical tube diameter and critical energy for direct blast initiation of gaseous detonations. J. Loss Prev. Process. Ind. 2013, 26, 1293-1299. Available online: http:/ / www.sciencedirect.com/ science/article/pii/S0950423013001496 (accessed on 13 July 2018). [CrossRef]

49. Matunga, A.; Yasuhara, A.; Shimizu, Y.; Wakakura, M.; Shibamoto, T. Investigation on the spontaneous combustion of refusederived fuels (RDF) during storage using a chemiluminescence technique. Waste Manage. Res. 2008, 26, 539-545. [CrossRef]

50. Hirunpraditkoon, S.; Dlugogorski, B.; Kennedy, E. Fire Properties of Refuse Derived Fuels: Measurements of Temperature Profiles and Mass Loss. Fire Saf. Sci. 2008, 9, 765-776. [CrossRef]

51. Babrauskas, V. Smoldering Fires; Fire Science Publisher: New York, NY, USA, 2021; ISBN 978-0-9728111-1-8.

52. Babrauskas, V. Ignition Handbook: Principles and Applications to Fire Safety Engineering, Fire Investigation, Risk Management and Forensic Science; Fire Science Publishers: Issaquah, WA, USA, 2003; ISBN 9780972811132.

53. Hilado, C.J. Flammability Handbook for Plastics. J. Coat. Fabr. 1981, 10, 254-254. [CrossRef] 
54. Gan, B.; Li, B.; Jiang, H.; Zhang, D.; Bi, M.; Gao, W. Ethylene/polyethylene hybrid explosions: Part 1. Effects of ethylene concentrations on flame propagations. J. Loss Prev. Process. Ind. 2018, 54, 93-102. Available online: https: / /www.sciencedirect. com/science/article/pii/S0950423018301256 (accessed on 13 July 2018). [CrossRef]

55. Im, E.J.; Kim, S.H.; Lee, K.-H. Optimization of pyrolysis conditions of polyurethane for recycling of solid products. J. Anal. Appl. Pyrolysis 2008, 82, 184-190. Available online: http:/ / www.sciencedirect.com/science/article/pii/S0165237008000296 (accessed on 13 July 2018). [CrossRef]

56. Tuomisaari, M.; Baroudi, D.; Latva, R. Extinguishing Smouldering Fires in Silos; VTT Building Technology; Technical Research Centre of Finland: Espoo, Finland, 1998. 